\title{
Transfer Teknologi Pembuatan Curriculum Vitae Dan Poster Untuk Siswa Pondok Pesantren Al- Munawwaroh
}

\author{
Aji Prasetya Wibawa, Muhammad Ashar, Syaad Patmanthara \\ Teknik Elektro Universitas Negeri Malang
}

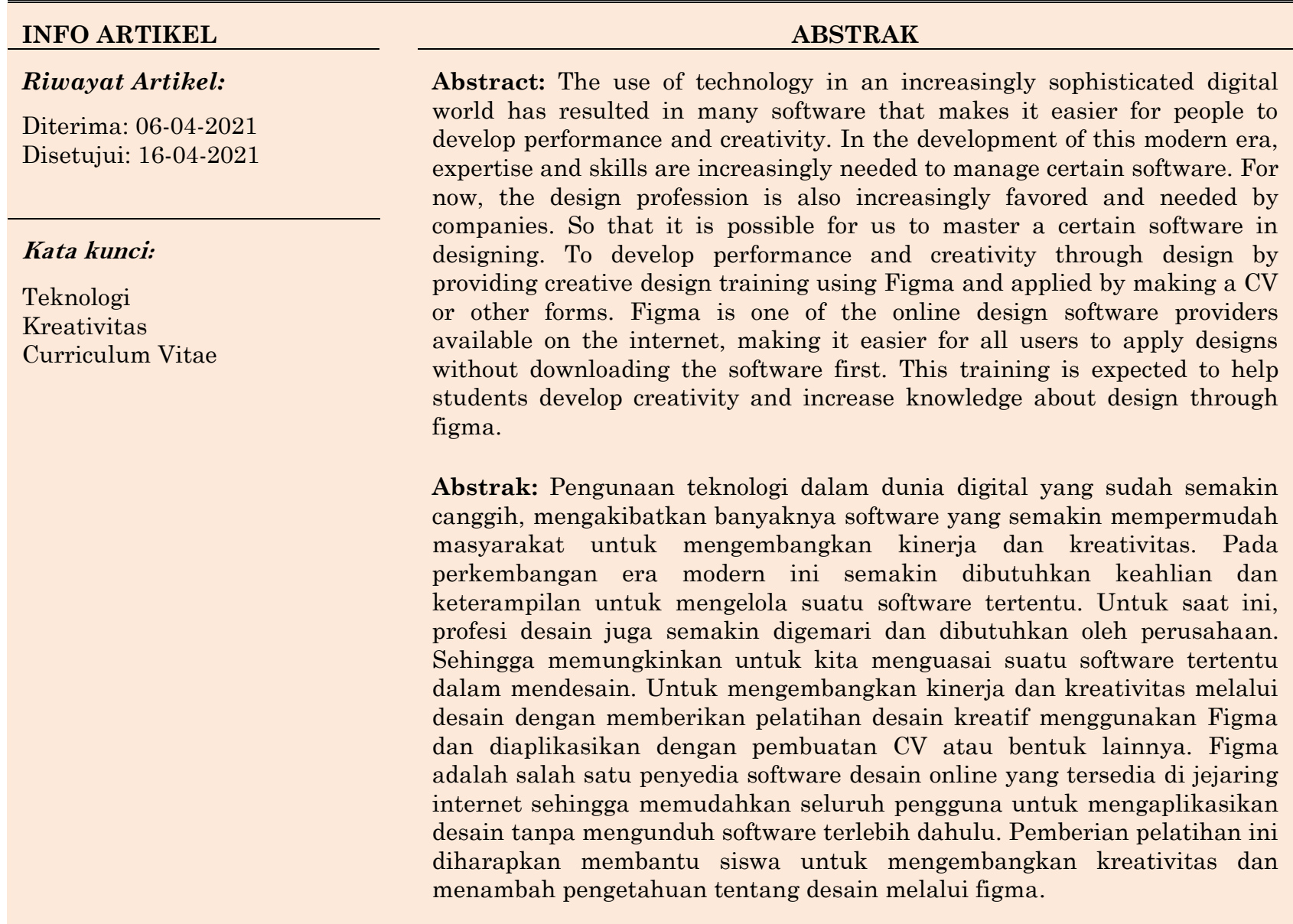

\section{Alamat Korespondensi:}

Aji Prasetya Wibawa,

Jurusan Teknik Elektro / S1 Teknik Informatika

Universitas Negeri Malang

Jln. Semarang No.5 Malang

E-mail: aji.prasetya.ft@um.ac.id

\section{PENDAHULUAN}

Desain merupakan kegiatan kreatif untuk merencanakan dan merancang sesuatu yang umumnya fungsional dan tidak ada sebelumnya dalam rangka menyelesaikan suatu masalah tertentu agar memiliki nilai lebih dan menjadi lebih bermanfaat bagi penggunanya (Sanjaya, 2015). Desain perlu dipelajari karena dapat 
menghasilkan uang, dengan Desain membuat sesuatu jadi lebih menarik, mengembangkan kreativitas, meringkas informasi agar lebih mudah dicerna, dan perlunya desain CV agar menambah ketertarikan perusahaan (Pribadi, 2016; Tinarbuko, 2015).

Resume pekerjaan adalah dokumen yang harus disiapkan selama proses pencarian kerja. Dokumen ini berisi informasi rinci tentang data pribadi seseorang, seperti nama lengkap, alamat, tanggal lahir, latar belakang pendidikan, dan pengalaman kerja. Tidak ada batasan panjang resume, yang terpenting adalah bagaimana dokumen ini berisi semua informasi yang menggambarkan pengalaman akademis dan profesional (Gallagher \& Wodlinger Jackson, 2010; Hutahaean, 2009).

Poster adalah suatu karya seni atau karya desain grafis yang memuat gambar dan huruf pada kertas besar atau kecil. Aplikasi dilakukan dengan menempelkannya ke dinding atau permukaan datar lainnya dengan karakteristik yang paling menarik perhatian. Oleh karena itu poster biasanya menggunakan warnawarna kontras dan warna-warna yang kuat. Poster bisa menjadi sarana periklanan, pendidikan, publisitas, sosialisasi dan dekorasi. Selain itu, juga bisa menjadi reproduksi dari karya seni terkenal (Irfan, 2015; Kusumawardani et al., 2018; Subianto et al., 2018).

Figma merupakan editor grafis vektor (alat untuk membuat pola) dengan berbasis web serta fitur offline tambahan yang terdapat di desktop untuk plattform Mac OS dan Windows. Aplikasi pendamping Figma Mirror yang tersedia di plattform Android dan iOS untuk dapat melihat desain Figma di perangkat seluler. Fitur yang terdapat pada Figma berfokus pada penggunaan antarmuka pengguna dan desain pengalaman pengguna dengan kolaborasi waktu nyata (real- time). Dapat diambil kesimpulan, Figma merupakan desain digital dan alat prototyping (Puspita, 2020; Terrell, 2019).

Dalam rangka mencapai dasar pemikiran dan tujuan tersebut, maka sebagai pengajar di bidang Informatika turut berperan aktif dengan menyelenggarakan kegiatan Workshop at School dengan tema "Show Your Talent In Your Design Using Figma" untuk menumbuhkan minat pelajar dalam dunia pengembangan desain sesuai pokok utama imajinasi dari masing-masing pelajar. Pelatihan ini diharapkan dapat membantu pelajar untuk lebih mengenal tentang dasar-dasar dari pembuatan Poster dan CV namun berdasar imajinasi mereka, serta dapat memanfaatkan dan mengimplementasikannya sesuai kebutuhan setiap individu kedepannya (Nugroho et al., 2010; Rohman \& Cahyadi, 2018).

\section{METODE}

Kegiatan workshop at school ini dilakukan dengan menggandeng mitra yaitu Pondok Pesantren AlMunawwaroh di Kedungkandang. Metode yang digunakan dalam kegiatan ini berdasar tujuan pelatihan yang telah disusun maka di susun langkah atau cara pelaksanaan sebagai berikut:

\section{Diskusi Antara Pihak Pelaksana dengan Sekolah}

Diskusi antara pihak sekolah dan tim pelaksana untuk sosialisasi program terhadap guru, maupun pihak sekolah tentang maksud, tujuan, dan metode pelaksanaan program. Diskusi juga digunakan untuk menggali informasi tentang kebutuhan terkait jalannya kegiatan. Diskusi dilakukan dengan Dosen Jurusan Teknik Elektro Universitas Negeri Malang. Selanjutnya hasil diskusi digunakan sebagai bahan untuk mempersiapkan pelaksanaan pembuatan aplikasi media interaktif.

\section{Persiapan dan Pelaksanaan Pembuatan Aplikasi}

Tahap ini digunakan oleh tim pelaksana untuk mempersiapkan segala kebutuhan yang akan digunakan pada pelaksanaan pembuatan aplikasi, mulai dari pembuatan desain alat sampai perlengkapan yang akan digunakan pada saat pembuatan aplikasi media interaktif.

\section{Pelaksanaan Pelatihan}

Kegiatan ini merupakan kegiatan diseminasi tentang penggunaan alat yang akan diberikan kepada Pondok Pesantren Al-Munawwaroh tersebut. Kegiatan pelatihan ini dilakukan dengan metode ceramah, tanya jawab, dan praktik. Metode ceramah dilakukan untuk memberikan pemahaman tentang teori dan konsep prinsip kerja aplikasi. Metode tanya jawab bertujuan untuk meningkatkan pemahaman tentang manfaat aplikasi dan prinsip kerjanya. Sedangkan metode praktik dilaksanakan untuk mempraktikkan pengoperasian figma. Untuk mengukur keberhasilan kegiatan pengabdian masyarakat ini, akan dilakukan evaluasi terhadap peserta dan evaluasi kegiatan. Evaluasi terhadap peserta terdiri dari evaluasi awal yang 
dilakukan dengan memberikan pretest kepada peserta dan evaluasi akhir yang diukur dari kemampuan peserta mengerjakan seluruh instruksi dalam lembar kerja pelatihan.

\section{HASIL}

Pelaksanaan "Transfer Teknologi Pembuatan Curriculum Vitae Dan Poster Untuk Siswa Pondok Pesantren Al-Munawwaroh" dilaksanakan pada hari Jumat, 17 Oktober 2020 diikuti oleh sebanyak 30 siswa Pondok Pesantren Al-Munawwaroh. Materi Pelatihan yang disampaikan berupa pembuatan CV dan Poster dengan mengutamakan desain gambar dasar melalui shape dan pengunaan warna melalui tools - tools yang ada sebagai variasi. Dalam kegiatan praktek ini peserta dibagi menjadi 5 kelompok dengan tiap-tiap kelompok beranggotakan 6 orang. Praktek ini bertujuan membimbing peserta untuk dapat membuat kreatifitas dan membuat Curriculum Vitae dan poster yang diperlukan untuk pencarian beasiswa studi lanjut ataupun kerja. Hasil kegiatan pelatihan yang berkaitan dengan bidang akademik adalah terjadi peningkatan pengetahuan dan pemahaman peserta pada saat sebelum dan sesudah melakukan pelatihan, hal ini dapat dilihat dari hasil praktek yang telah dilakukan dan peserta yang mengikuti dengan antusias (Gallagher \& Wodlinger Jackson, 2010; Subianto et al., 2018).

Tabel 1. Hasil Evaluasi Transfer Teknologi

\begin{tabular}{|c|c|c|c|c|c|}
\hline \multirow[b]{2}{*}{ No. } & \multicolumn{5}{|c|}{ I. $\quad$ Respon Participant (\%) } \\
\hline & II. Indikator & $\begin{array}{l}\text { III. } \mathbf{T} \\
\mathbf{B}\end{array}$ & $\begin{array}{c}\text { IV. K } \\
\text { B }\end{array}$ & V. B & $\begin{array}{c}\text { VI. S } \\
\text { B }\end{array}$ \\
\hline 1 & Kehadiran trainer & & & 10.5 & 89.5 \\
\hline 2 & $\begin{array}{l}\text { Pemahaman trainer } \\
\text { terhadap isi pelatihan }\end{array}$ & & & 13.2 & 86.8 \\
\hline 3 & $\begin{array}{l}\text { Pemahaman peserta } \\
\text { terhadap penyampaian } \\
\text { materi }\end{array}$ & & & 39.5 & 60.5 \\
\hline 4 & $\begin{array}{l}\text { Suasana pelatihan yang } \\
\text { komunikatif }\end{array}$ & & 2.6 & 26.3 & 71.1 \\
\hline 5 & Kesiapan trainer & & & 21.1 & 78.9 \\
\hline Rata & & & 0.52 & 22.1 & 77 \\
\hline
\end{tabular}

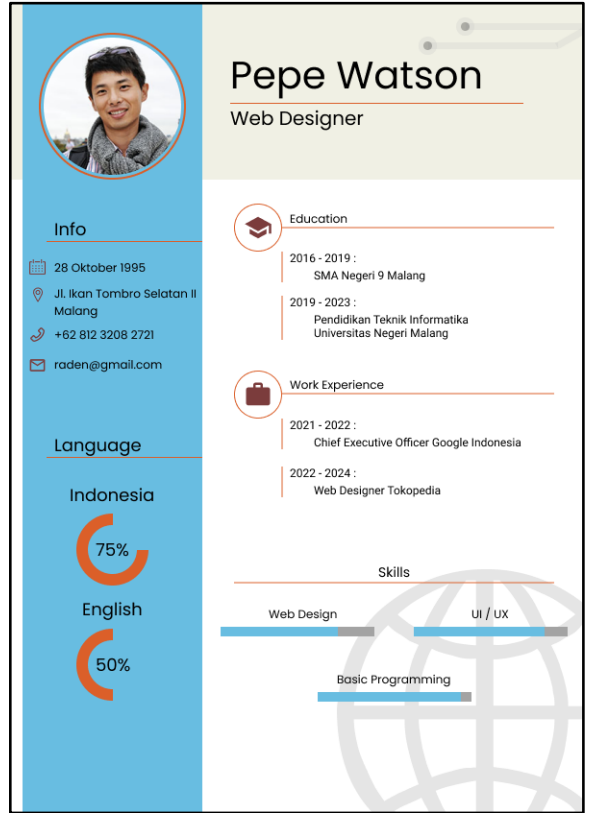

(a). Produk Curriculum Vitae

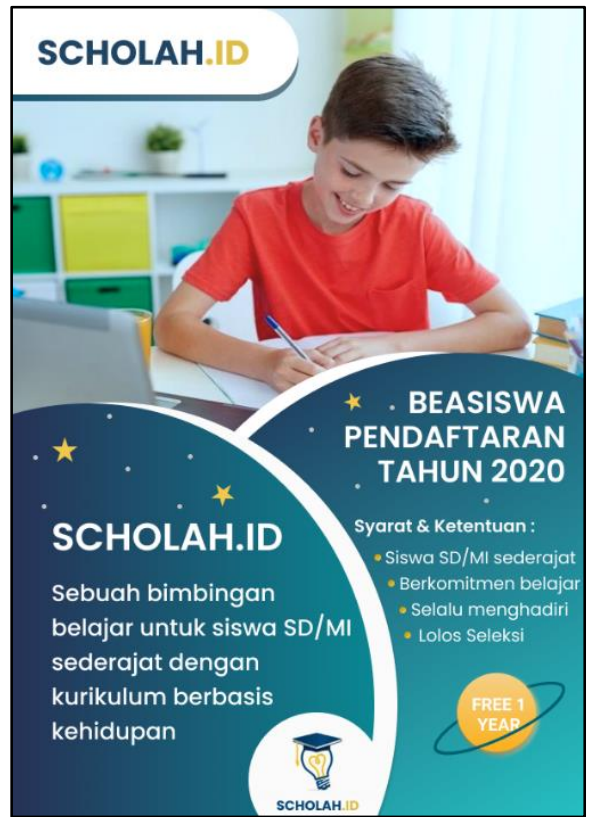

(b). Produk Poster 
Gambar 1. Contoh Hasil Produk Pelatihan
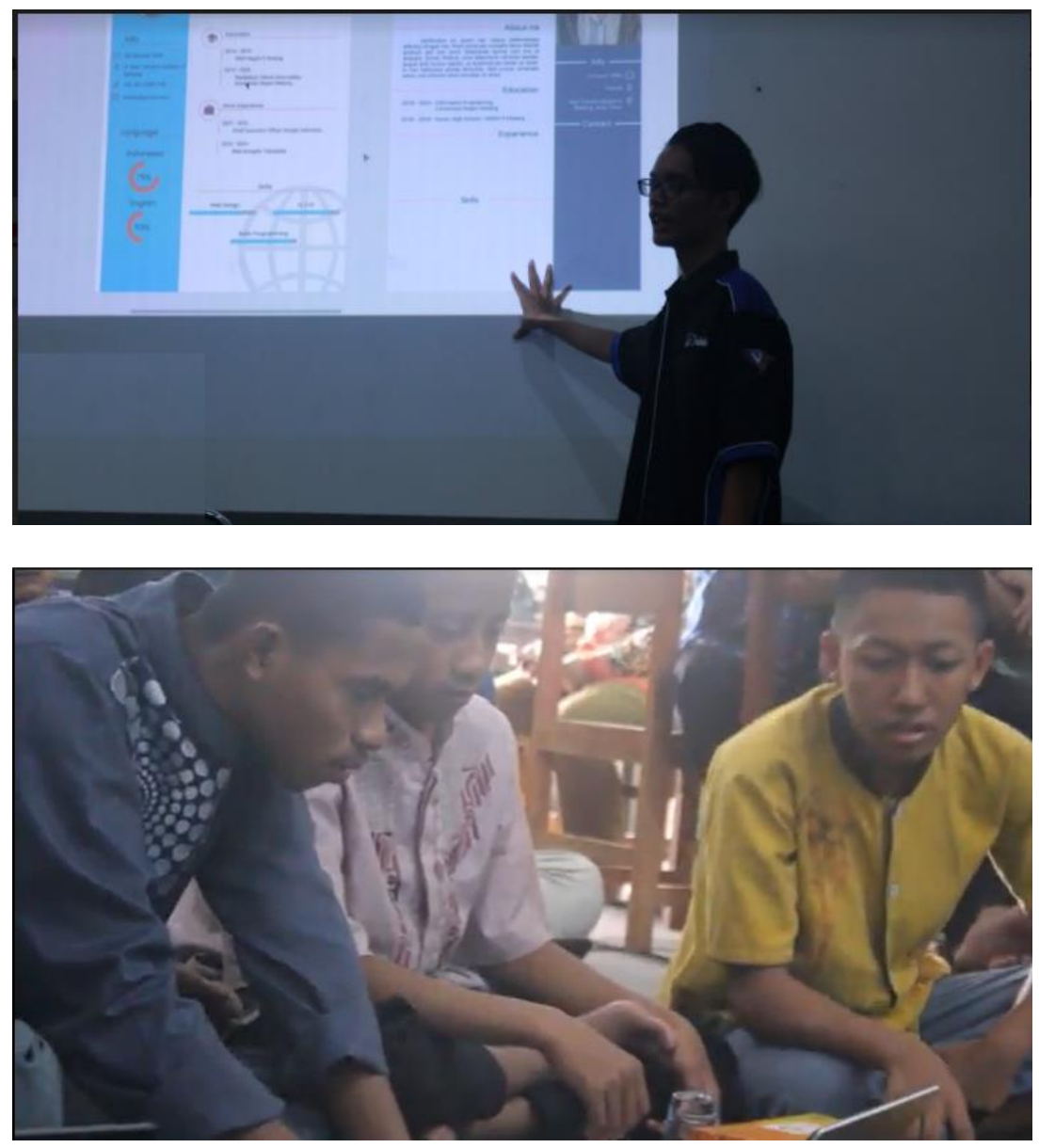

Gambar 2. Suasana Pelatihan

\section{PEMBAHASAN}

Kegiatan pelatihan pembuatan curriculum vitae dan poster untuk siswa pondok pesantren almunawwaroh telah terlaksana dengan baik, meskipun terhambat berbagai hambatan selama proses pelaksanaanya. Dimulai dari persiapan kegiatan hingga pelaksanaan teknis. Materi yang diberikan adalah cara mendesain curriculum vitae dan poster. Hal ini dipilih karena curriculum vitae dan poster merupakan hal yang cukup penting yang dalam kegiatan kegiatan yang kita jalani sehingga sangat berguna jika kita menguasai skill mendesain tersebut. untuk tools yang digunakan dalam pelatihan desian yaitu menggunakan aplikais figma. Penggunaan aplikasi figma untuk kegiatan ini karena aplikasi tersebut mudah untuk digunakan untuk belajar desain, bisa dipakai untuk semua spek komputer karena berbasis website, serta kita dapat berkolaborasi bersama tim dalam satu projek untuk membuat suatu projek. Siswa pondok pesantren al munnawaroh pun juga menyimak dengan seksama materi materi yang diberikan selama kegiatan berlangsung. Dari keseluruhan kegiatan rata-rata respon dari siswa menyatakan Kurang Bagus (KB) 0.52, Bagus (B) 22.1 dan 77 Sangat Bagus (SB).

\section{SIMPULAN}

Berdasarkan hasil kegiatan "Transfer Teknologi Pembuatan Curriculum Vitae Dan Poster Untuk Siswa Pondok Pesantren Al-Munawwaroh" dapat ditarik kesimpulan bahwa emahaman siswa Pondok Pesantren AlMunawwaroh terhadap transfer teknologi didapatkan siswa menyatakan Kurang Bagus (KB) 0.52, Bagus (B) 22.1 dan 77 Sangat Bagus (SB). Kemudian kemampuan siswa Pondok Pesantren Al-Munawwaroh 
mengalamai peningkatan, dimana setiap kelompok guru telah berhasil membuat gambar dan slide presentasi untuk memvariasikan media belajarnya.

\section{DAFTAR RUJUKAN}

Gallagher, J. C., \& Wodlinger Jackson, A. M. (2010). How to write a curriculum vitae. American Journal of Health-System Pharmacy, 67(6), 446-447.

Hutahaean, E. S. H. (2009). Sistem Informasi Psikologi Industri: Menyeleksi Aplikasi Resume Pekerjaan Dengan Cara Yang Tepat Dan Objektif. Proceeding PESAT (Psikologi, Ekonomi, Sastra, Arsitektur \&Sipil), 3.

Irfan, I. (2015). Perpaduan Elemen-Elemen Desain Pada Karya Desain Poster Mahasiswa (Studi Kasus pada Tugas Poster Mata Kuliah Penulisan Naskah Iklan Dkv Fsd Unm Angkatan 2011). Tanra, 2(02), 54-68.

Kusumawardani, N., Siswanto, J., \& Purnamasari, V. (2018). Pengaruh model pembelajaran kooperatif tipe STAD berbantuan media poster terhadap hasil belajar peserta didik. Jurnal Ilmiah Sekolah Dasar, 2(2), 170-174.

Nugroho, P. S., Cahyadin, M., Perindustrian, D., Kebudayaan, D., \& Pariwisata, D. K. (2010). Analisis Perkembangan Industri Kreatif Di Indonesia. Simposium Ekonomi Indonesia Pasca Krisis Ekonomi Global, Surabaya.

Pribadi, B. A. (2016). Desain dan pengembangan program pelatihan berbasis kompetensi implementasi model ADDIE. Kencana.

Puspita, R. (2020). Pengembangan prototipe aplikasi community aggregator beskem dengan pendekatan ucd menggunakan balsamiq mockup dan FIGMA (studi kasus: PT Mozaik Bintang Persada). Fakultas Sains dan Teknologi Universitas Islam Negeri Syarif Hidayatullah ....

Rohman, M. Z., \& Cahyadi, D. (2018). Pemanfaatan Komputer Grafis Menggunakan Software Corel Draw Dalam Pembelajaran Pembuatan Poster Dan Spanduk. Prosiding Semnas PPM 2018, 1(1), 1007-1012.

Sanjaya, W. (2015). Perencanaan dan desain sistem pembelajaran. Kencana.

Subianto, I. B., Anto, P., \& Akbar, T. (2018). Perancangan poster sebagai media edukasi peserta didik. Jurnal Desain, $5(03), 215-222$.

Terrell, J. (2019). Comp 523 lab: using Figma 6.

Tinarbuko, I. T. S. (2015). Dekave: Desain Komunikasi Visual Penanda Zaman Masyarakat Global. CAPS. 